\title{
TRATAMENTO PRESERVATIVO DA MADEIRA JUVENIL DE Eucalyptus camaldulensis Dehnh. PELO MÉTODO DE SUBSTITUIÇÃO DE SEIVA
}

\author{
Pablo Marcel de Arruda Torres ${ }^{1}$, Juarez Benigno Paes ${ }^{2}$, José Augusto de Lira Filho ${ }^{3}$, \\ José Wallace Barbosa do Nascimento ${ }^{4}$
}

(recebido: 20 de outubro de 2009; aceito: 29 de março de 2011)

\begin{abstract}
RESUMO: Objetivou-se, com esta pesquisa, analisar a qualidade do tratamento preservativo da madeira juvenil de Eucalyptus camaldulensis Dehnh. e verificar a influência da inversão das peças na solução preservativa, na distribuição, na penetração e na retenção do CCB, ao longo das peças tratadas pelo método de substituição de seiva. Árvores de Eucalyptus camaldulensis foram coletadas na Zona Rural do Município de Rio Tinto - PB, de um povoamento com quatro anos. No povoamento foram escolhidas, aleatoriamente, cinco árvores, sendo três de maior diâmetro. Para o tratamento da madeira, empregou-se o método de substituição de seiva por transpiração radial utilizando-se uma solução de $2 \%$ de ingredientes ativos de borato de cobre cromatado $(\mathrm{CCB})$ e comparou-se o efeito da inversão das peças na solução preservativa. A distribuição, a penetração e a retenção foram melhores nas peças invertidas, quando comparadas àquelas não-invertidas na solução preservativa.
\end{abstract}

Palavras-chave: Tratamento de madeira, CCB, análise química.

\section{PRESERVATIVE TREATMENT OF Eucalyptus camaldulensis Dehnh. JUVENILE WOOD BY SAP DISPLACEMENT METHOD}

\begin{abstract}
The research analyzed the quality of the preservative treatment of Eucalyptus camaldulensis Dehnh juvenile wood and verified the influence of the inversion of the pieces, in preservative solution, in the distribution, penetration and retention of CCB in treated pieces. Trees of Eucalyptus camaldulensis were collected in the rural area of the municipality of Rio Tinto, Paraíba, Brazil, in a stand aged four years. In the stand were randomly chosen five trees, being three of them with the larger diameter. For the wood treatment it was used the sap displacement method by radial transpiration using a $2 \%$ solution of ingredients copper chrome borate (CCB) and compared the effect of the inversion of pieces on the preservative solution. The distribution, penetration and retention were better in reversed pieces when compared with the ones non-reversed in the preservative solution.
\end{abstract}

Key words: Wood treatment, CCB, chemistry analysis.

\section{INTRODUÇÃO}

O eucalipto foi introduzido no Brasil no final da década de 1870 com plantios de caráter cênico de pouquíssimos indivíduos. Apenas em 1903, iniciou-se o plantio em escala considerável visando ao fornecimento de madeira para produção de dormentes de linhas ferroviárias (TEREZO, 2001).

No início da década de 1960, o Governo Brasileiro decidiu estimular a produção de papel e celulose, até então importados. Em 1966 já havia cerca de 400 mil hectares de florestas plantadas. Nesse mesmo ano, o Governo Federal lançou um programa de incentivo ao plantio de eucalipto para atender a necessidades energéticas e de matéria-prima para a indústria. Em 1988 o Brasil possuía cerca de 6,2 milhões de hectares reflorestados; sendo 3,25 milhões de hectares reflorestados com eucalipto (AZEREDO, 1998). O país tinha a maior disponibilidade imediata de florestas em idade de corte do mundo, com $22 \%$ do reflorestamento mundial de eucaliptos (FLYNN; SHIELD, 1999).

Dos 263,5 milhões de $\mathrm{m}^{3}$ de madeira sólida foram consumidos no Brasil em 1990, a participação da madeira de eucaliptos foi da ordem de 64,3 milhões de $\mathrm{m}^{3}$ e se iniciava o emprego do eucalipto como matéria-prima para uso em estruturas diversas (FERREIRA, 1993).

\footnotetext{
${ }^{1}$ Designer, Professor Mestre em Engenharia Agrícola - Unidade Acadêmica de Desenho Industrial - Universidade Federal de Campina Grande Cx. P. 10.078 - 58109-970 - Campina Grande, PB - pablo.marcel@gmail.com

${ }^{2}$ Engenheiro Florestal, Professor Dr. em Ciência Florestal - Departamento de Engenharia Florestal - Universidade Federal do Espírito Santo Av. Gov. Lindemberg, 316 - 29550-000 - Jerônimo Monteiro, ES - jbp2@uol.com.br

${ }^{3}$ Engenheiro Florestal, Professor Dr. em Ciência Florestal - Unidade Acadêmica de Engenharia Florestal - Universidade Federal de Campina Grande Campus de Patos - Cx. P. 64 - 58700-970 - Patos, PB - augustoufcg@yahoo.com.br

${ }^{4}$ Engenheiro Agrícola, Professor Dr. em Engenharia Civil - Unidade Acadêmica de Engenharia Agrícola - Universidade Federal de Campina Grande Cx. P. 10.078 - 58109-970 - Campina Grande, PB - wallace@deag.ufcg.edu.br
} 
Essa madeira é empregada com frequência, na arquitetura rural, na solução de problemas relacionados à cobertura de telhados, travessia de obstáculos (pontes, viadutos, passarelas para pedestres), armazenamento (silos verticais e horizontais), linhas de transmissão (energia elétrica, telefonia), benfeitorias rurais, entre outros (CALIL JÚNIOR; DIAS, 1997).

A madeira da maioria das espécies de eucalipto é susceptível ao ataque de organismos deterioradores, necessitando de tratamento químico que lhe forneça proteção contra fungos e insetos xilófagos (brocas e cupins) e que, consequentemente, aumente sua vida útil. Para esse fim, são utilizados, comumente, produtos químicos que se fixam na madeira, tornando-a mais resistente à ação destes agentes biológicos, sobretudo se a madeira ficar em contato direto com o solo ou água (SILVA, 2005).

Os métodos de tratamento podem ser classificados em não-industriais ou industriais (com a utilização de equipamentos específicos). Dentre os métodos nãoindustriais se destaca o de substituição de seiva por transpiração radial, em função de sua operacionalidade e baixo custo das instalações (FARIAS SOBRINHO et al., 2005). Este método consiste em substituir a seiva da madeira ainda verde pela solução preservativa. Desta forma, é conveniente que o tratamento seja realizado no máximo 24 horas após o corte da árvore. É um processo de tratamento muito utilizado em pequenas propriedades para o tratamento de moirões.

No tratamento se emprega madeira verde, roliça e descascada, a qual é disposta verticalmente em tambores, tendo a base submersa na solução. Após o tratamento, os moirões devem passar pelo processo de secagem ao ar livre. Um dos produtos mais utilizados para este fim é o borato de cobre cromatado - CCB (MAGALHÃES; PEREIRA, 2003).

Dentre os critérios utilizados para se avaliar a eficiência de um tratamento preservativo, a quantidade de produto químico retido pela madeira e a profundidade de penetração têm sido muito empregados (HUNT; GARRATT, 1967). A capacidade de penetração da solução de tratamento é determinada pela profundidade da camada tóxica e depende do sistema de impregnação, da umidade e das características da madeira, além da natureza do produto químico empregado. De maneira geral, a penetração média deve ser superior a $1,0 \mathrm{~cm}$ de profundidade (FARIAS SOBRINHO et al., 2005; PAES et al., 2005; WEHR, 1985).

Cerne, Lavras, v. 17, n. 2, p. 275-282, abr./jun. 2011
A retenção é o fator mais importante para se avaliar a qualidade de um tratamento preservativo. De modo geral, as retenções mínimas de preservativos hidrossolúveis devem ser de 5 a $16 \mathrm{~kg} / \mathrm{m}^{3}$ de madeira tratada (HUNT; GARRATT, 1967). A Norma Brasileira Regulamentadora - NBR 9480, da Associação Brasileira de Normas Técnicas - ABNT (2009) cita que a retenção deve ser de, pelo menos, $6,5 \mathrm{~kg}$ de ingredientes ativos/ $\mathrm{m}^{3}$ de madeira para peças a serem utilizadas em contato com o solo.

Além do emprego da madeira de eucalipto para construções e benfeitorias rurais, com o surgimento e expansão de hotéis fazendas, a mesma vem sendo empregada para a confecção de moveis rústicos para ambientes internos e externos, aproveitando-se na fabricação dos móveis, a forma natural da madeira, em que as peças podem receber tratamento preservativo e acabamento simples (vernizes, óleos e ceras). Os móveis rústicos são versáteis sendo utilizados na composição de interiores (sala e cozinha) e exteriores (jardins e áreas de lazer), onde a madeira, caso receba o devido tratamento, poderá constituir artefatos de grande durabilidade e resistência, além de combinar com a paisagem natural.

Em função da importância da madeira de eucalipto para os mais diversos usos, objetivou-se, com esta pesquisa, analisar a qualidade do tratamento preservativo da madeira juvenil de Eucalyptus camaldulensis Dehnh. e verificar a influência da inversão de peças roliças, na solução preservativa, na distribuição, penetração e retenção do $\mathrm{CCB}$, ao longo das peças tratadas.

\section{MATERIAL E MÉTODOS}

\subsection{Procedência, seleção e abate das árvores}

As árvores de Eucalyptus camaldulensis Dehnh. foram coletadas na propriedade da Cerâmica Cincera, localizada na Zona Rural do Município de Rio Tinto, PB (latitude $6^{\circ} 48^{\prime} 27^{\prime \prime} \mathrm{S}$ e longitude $35^{\circ} 04^{\prime} 05^{\prime \prime} \mathrm{W}$ ). No povoamento, foram escolhidas, aleatoriamente, cinco árvores, sendo três de maior diâmetro. As árvores eram jovens, com cerca de quatro anos de idade (plantadas em julho de 2003 e abatidas em novembro de 2007) e tinham, em média, 20 metros de altura total.

As árvores foram abatidas com motosserra e, após o abate, os troncos foram subdivididos em toras de quatro metros de comprimento, cada árvore deu origem a quatro toras. 


\subsection{Descascamento e destino das toras}

As toras foram transportadas para a Universidade Federal de Campina Grande - UFCG, Campus de Patos, Patos, PB, onde foram descascadas. Depois de descascadas, as toras mais finas, provenientes da terceira ou quarta secção do tronco, foram destinadas ao tratamento preservativo. Para este caso, depois de descascadas, tiveram a camada de câmbio vascular removida e seus comprimentos ajustados para 2,0 metros.

\subsection{Tratamento preservativo das peças}

A madeira foi tratada no Laboratório de Tecnologia de Produtos Florestais (LTPF) da Unidade Acadêmica de Engenharia Florestal (UAEF) da UFCG, localizado no Campus de Patos e realizados ensaios de penetração e o preparo das amostras, para as leituras da retenção.

O método de tratamento empregado foi o de substituição de seiva por transpiração radial ao empregar produto à base de borato de cobre cromatado (CCB), hidrossolúvel na forma de pasta, de ação fungicida e inseticida. Escolheu-se esse método em função da facilidade de aplicação e da disponibilidade de material para sua realização no meio rural. O preservativo $\mathrm{CCB}$, segundo a ABNT (2009), tem sua composição química especificada como: cromo hexavalente, calculado como $\mathrm{CrO}_{3}(63,5 \%)$; cobre, calculado como $\mathrm{CuO}(26,0 \%)$; e boro, calculado como B (10,5\%).

Para o tratamento, foram selecionadas, aleatoriamente, 10 peças com comprimento de 2,0 m, que foram identificadas e imediatamente submetidas ao tratamento, que teve início 24 horas após o abate das árvores. No tratamento, as peças foram dispostas verticalmente em um tambor de 200 litros. Preparou-se, em outro tambor, uma solução a $2,0 \%$ de concentração de ingredientes ativos de CCB. Adicionou-se a solução preservativa de forma que as peças ficassem parcialmente submersas, $50 \mathrm{~cm}$ da base, e com suas porções aéreas separadas para facilitar a circulação de ar e a evaporação da seiva.

Foram adicionados, ao tambor, $500 \mathrm{~mL}$ de óleo vegetal a fim de evitar a evaporação da água da solução preservante e de manter constante o nível inicial de solução nos recipientes. Na proporção em que a solução era absorvida pelas peças, procedeu-se à reposição da solução preservante.

As peças foram submetidas a duas situações (nãoinvertida e invertida). Na situação não-invertida, elas permaneceram, durante oito dias, na solução de tratamento, sem que houvesse a inversão das mesmas na solução; já na situação invertida, estas tiveram sua posição inicial invertida, após o sexto dia de tratamento, permanecendo no tratamento por mais dois dias, a fim de completar o tempo de tratamento estipulado de oito dias.

\subsection{Amostragem e análise das peças tratadas}

Após a secagem ao ar, foram extraídos dois discos, em três posições ao longo das peças: a $50 \mathrm{~cm}$ da base (posição 1), no meio do comprimento (posição 2) e a 10 $\mathrm{cm}$ do topo (posição 3) (Figura 1). Um disco foi utilizado para o ensaio de penetração e distribuição e o outro para retenção, com a finalidade de verificar o tratamento recebido ao longo do comprimento das peças. Os discos foram identificados em relação à posição na peça e situação de tratamento (não-invertida e invertida).

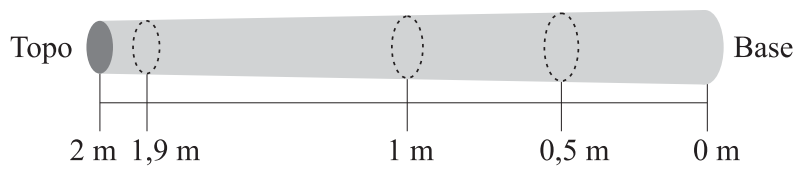

Figura 1 - Posições na peça onde foram retirados os discos para as análises químicas.

Figure 1 - Positions in the wood pieces where the disks were taken for the chemical analyses.

\subsubsection{Penetração e distribuição do cobre nas peças tratadas}

Para permitir a leitura e medição da penetração do preservativo na madeira, os discos foram previamente lixados e marcados com linhas perpendiculares entre si, que se cruzavam na medula da amostra.

A penetração do CCB foi avaliada em função da presença do cobre, por apresentar reação mais nítida que o boro (PAES et al., 2005). A fim de verificar a penetração do cobre, aplicou-se, sobre os discos, uma solução à base de "cromo-azurol S", seguindo-se as especificações da NBR 6232 da ABNT (1973). A penetração do cobre em cada disco foi medida, com auxílio de uma régua milimétrica sobre as linhas demarcadas, realizando-se leituras em quatro pontos, sendo a média das leituras o valor da penetração do elemento na madeira.

\subsubsection{Retenção de CCB nas peças tratadas}

Para a determinação da retenção da solução preservativa, selecionaram-se, aleatoriamente, três peças de cada situação (invertida ou não-invertida) e foram retirados discos em três posições das peças (Figura 1). 
De cada disco, foram tomadas quatro amostras na direção radial à medula, com dimensões de 1,5 x 1,5 x 2,0 cm (radial x tangencial x longitudinal) (Figura 2).

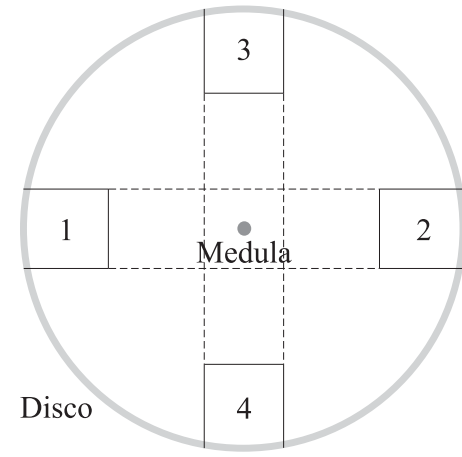

(a)

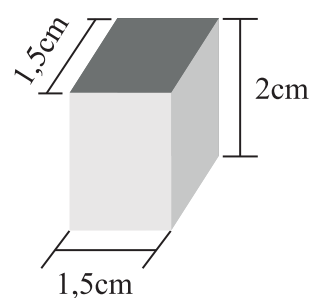

(b)
Figura 2 - Posição (a) e dimensões (b) das amostras retiradas para a análise de retenção.

Figure 2 - Position (a) and dimensions (b) of samples taken for the solution retention analyses.

As amostras foram identificadas e duas delas, tomadas ao acaso, foram empregadas para determinação da retenção; em seguida, se determinaram os volumes das amostras por meio do método de deslocamento em mercúrio (VITAL, 1984).

Conforme metodologia descrita por Wischer, citado por Moreschi (1985), as amostras sorteadas passaram pelo processo de digestão, que se iniciou com a incineração das amostras para obtenção das cinzas e de sais metálicos em um forno mufla, em temperatura variando entre $500 \mathrm{e}$ $550^{\circ} \mathrm{C}$ até a transformação em cinzas.

Após a digestão, foram adicionados às cinzas 3 $\mathrm{mL}$ da mistura dos ácidos sulfúrico, perclórico e nítrico, todos na forma concentrada, na proporção de 7:2:1, respectivamente. Em seguida, procedeu-se à digestão acelerada por meio do aquecimento da mistura dos ácidos e cinzas, em chapa aquecida, até a mistura ficar límpida. As soluções resultantes foram diluídas em água destilada em volume fixo de $100 \mathrm{~mL}$ e armazenadas em frascos plásticos devidamente identificados.

Os frascos contendo as amostras diluídas foram enviados para leitura de espectrometria de absorção atômica, no Laboratório de Química e Fertilidade do Solo (LQFS), Centro de Ciências Agrárias, Campus II da Universidade Federal da Paraíba, localizado em Areia - PB.

Cerne, Lavras, v. 17, n. 2, p. 275-282, abr./jun. 2011
Com os dados das leituras e os volumes das amostras, efetuaram-se os cálculos de retenção, conforme a Equação 1 (PAES et al., 2005).

$$
R=\frac{F \times L \times F d \times 10^{-3}}{V}
$$

em que:

$R=$ Retenção do elemento na madeira, em $\mathrm{kg} / \mathrm{m}^{3}$;

$F=$ Fator estequiométrico empregado para transformação dos elementos químicos para óxidos (cobre x 1,2518= $\mathrm{CuO}$, cromo x $1,9230=\mathrm{CrO}_{3}$ );

$L=$ Leitura obtida do espectrofotômetro de absorção atômica, em $\mathrm{mg} / \mathrm{L}$;

$F d=$ Fator de diluição; e

$V=$ Volume das amostras utilizadas nas análises $\left(\mathrm{cm}^{3}\right)$.

\subsection{Análise dos resultados}

No experimento, empregou-se o delineamento inteiramente casualizado com arranjo fatorial, em que foram analisadas as situações de tratamento, com 2 níveis (não-invertida e invertida); as penetrações e retenções na madeira, com 3 níveis (base, meio e topo); e 5 ou 3 repetições (penetração ou retenção), totalizando 30 ou 18 análises para as 10 peças tratadas.

Os valores de penetração e de retenção do preservativo foram analisados para verificar a existência de diferenças significativas entre as situações, posições nas peças e a existência de interações significativas entre os fatores analisados. Nas análises e avaliação dos ensaios realizados, empregou-se o teste de Tukey, em nível de 5\% de probabilidade.

\section{RESULTADOS E DISCUSSÃO}

\subsection{Distribuição do elemento cobre nas peças tratadas}

O preservativo se distribuiu nas peças de forma diferente entre as duas situações de tratamento. As peças que não foram invertidas apresentaram distribuição gradual, visto que a maior penetração ocorreu na posição 1 (50 cm da base), seguida da posição 2 (meio da peça) e menor na posição 3 (10 cm do topo), fato que pode ter ocorrido em virtude da parte inferior ter permanecido submersa na solução preservativa enquanto a superior se manteve fora da solução. Esse comportamento também foi observado por Farias Sobrinho et al. (2005), em peças roliças de algaroba (Prosopis juliflora) e por Paes et al. (2005), em peças de Eucalyptus viminalis e de bracatinga (Mimosa scabrella) submetidos ao processo de substituição de seiva por transpiração radial. 
O preservativo penetrou na madeira pela parte inferior e alcançou a parte superior por capilaridade. Como este processo é irregular, ou seja, a parte inferior da peça é a primeira a translocar a água, absorvendo antes o preservativo, é natural que as peças da posição 1 tenham mais produto que as demais. Resultados semelhantes foram observados por Farias Sobrinho et al. (2005) e por Paes et al. (2005).

Por outro lado, as peças que sofreram inversão mostraram maior homogeneidade na distribuição da solução preservativa e as extremidades das peças (posições 1 e 3) tiveram penetrações similares, pois ambas passaram por um período em contato com a solução preservativa e em contato com o ar.

A distribuição do produto químico na posição 1 das peças foi mais homogênea que na posição 3, provavelmente, em função da posição 1 ter sido a primeira a entrar em contato com a solução, penetrando de forma mais homogênea. Quando as peças foram invertidas, os vasos da madeira se encontravam parcialmente ocupados pela solução e, por terem permanecido expostos ao ar, houve o desenvolvimento de bolhas de ar no interior dos mesmos, aumentando a tensão superficial, em função das forças capilares desenvolvidas e dificultando a absorção da solução preservativa, o que contribuiu para que a distribuição na parte superior ocorresse de forma irregular. Este comportamento da madeira está de acordo com o citado por Wehr (1985).

\subsection{Penetração do elemento cobre nas peças tratadas}

Nas peças não-invertidas (Tabela 1), a penetração decresceu da base para o topo, não atingindo, nesta posição, em nenhuma das peças, a penetração de $1,0 \mathrm{~cm}$, considerada por Farias Sobrinho et al. (2005), Paes et al. (2005) e Wehr (1985), como a mínima necessária para proteger a madeira. Já as peças que foram invertidas na solução apresentaram penetração superior a $10 \mathrm{~cm}$, em todas as posições analisadas, para a maioria das peças tratadas.

Os valores de penetração (Tabela 1) foram analisados estatisticamente (Tabela 2) e observaram-se diferenças significativas na penetração nas diferentes posições da peça e entre as situações (invertidas e nãoinvertidas). As médias dos fatores posição e inversão das peças foram analisadas pelo teste de Tukey a 5\% de probabilidade (Tabela 3 ).

Com relação à posição, os valores apresentados na Tabela 3 demonstraram que os discos provenientes das porções inferiores das peças (posição 1) apresentaram maior penetração de cobre que as intermediárias e superiores (posições 2 e 3, respectivamente). Este comportamento é natural, visto que a base das peças permaneceu, durante maior período de tempo, em contato com a solução de tratamento, como o relatado por Farias Sobrinho et al. (2005) e Paes et al. (2005).

Tabela 1 - Penetrações médias (mm) para as situações e posições nas peças tratadas.

Table 1 - Penetration averages ( $\mathrm{mm}$ ) to situations and positions on treated pieces.

\begin{tabular}{|c|c|c|c|c|c|}
\hline \multirow{2}{*}{ Situações } & \multicolumn{3}{|c|}{$\begin{array}{l}\text { Penetrações medidas por } \\
\text { posição }(\mathrm{mm})\end{array}$} & \multicolumn{2}{|c|}{$\begin{array}{c}\text { Penetração na } \\
\text { peça }(\mathrm{mm})\end{array}$} \\
\hline & $\begin{array}{c}1 \\
\text { (Base) }\end{array}$ & $\begin{array}{c}2 \\
\text { (Meio) }\end{array}$ & $\begin{array}{c}3 \\
\text { (Topo) }\end{array}$ & Média & $\begin{array}{l}\mathrm{CV} \\
(\%)\end{array}$ \\
\hline \multirow{5}{*}{$\begin{array}{l}\text { (1) } \\
\text { Não-Invertida }\end{array}$} & 22,75 & 17,25 & 8,75 & 16,25 & 7,05 \\
\hline & 17,00 & 8,75 & 2,75 & 9,50 & 7,15 \\
\hline & 26,25 & 18,50 & 5,75 & 16,83 & 10,35 \\
\hline & 21,75 & 12,75 & 5,75 & 13,42 & 8,02 \\
\hline & 19,25 & 12,25 & 4,25 & 11,92 & 7,51 \\
\hline Média & 21,40 & 13,90 & 5,45 & 13,58 & 8,02 \\
\hline CV (\%) & 16,45 & 28,56 & 40,73 & 28,58 & 16,95 \\
\hline \multirow{5}{*}{$\begin{array}{l}(2) \\
\text { Invertida }\end{array}$} & 21,75 & 12,00 & 19,25 & 17,67 & 5,06 \\
\hline & 20,50 & 16,50 & 28,25 & 21,75 & 5,97 \\
\hline & 37,25 & 30,25 & 13,00 & 26,83 & 12,48 \\
\hline & 26,25 & 18,50 & 11,00 & 18,58 & 7,63 \\
\hline & 18,00 & 9,50 & 18,50 & 15,33 & 5,06 \\
\hline Média & 24,75 & 17,35 & 18,00 & 20,03 & 7,24 \\
\hline CV (\%) & 30,71 & 46,34 & 37,33 & 38,13 & 42,98 \\
\hline
\end{tabular}

Tabela 2 - Análise de variância da penetração ( $\mathrm{mm}$ ) do cobre nas peças tratadas.

Table 2 - Variance analysis of copper penetration $(\mathrm{mm})$ in treated pieces.

\begin{tabular}{lcccr}
\hline $\begin{array}{l}\text { Fontes de } \\
\text { Variação }\end{array}$ & $\begin{array}{c}\text { Graus de } \\
\text { Liberdade }\end{array}$ & $\begin{array}{c}\text { Soma de } \\
\text { Quadrados }\end{array}$ & $\begin{array}{c}\text { Quadrados } \\
\text { Médios }\end{array}$ & F \\
\hline Posição & 2 & 671,40 & 335,70 & 10,13 ** \\
Situação & 1 & 318,50 & 318,50 & 9,61 ** \\
Pos x Sit & 2 & 141,12 & 70,56 & 2,13 Ns \\
Resíduos & 24 & 795,40 & 33,14 & \\
Total & 29 & 1926,42 & & \\
\hline
\end{tabular}

** significativo a $1 \%$ de probabilidade; ${ }^{\text {NS }}$ não significativo a $5 \%$ de probabilidade.

Cerne, Lavras, v. 17, n. 2, p. 275-282, abr./jun. 2011 
Tabela 3 - Comparações entre penetrações $(\mathrm{mm})$ para as situações e posições nas peças.

Table 3 - Comparisons among penetrations $(\mathrm{mm}$ ) to conditions and positions in the wood pieces.

\begin{tabular}{lc}
\hline Posições nas peças & Penetrações $(\mathrm{mm})$ \\
\hline 1 (Base) & $23,08 \mathrm{a}$ \\
2 (Meio) & $15,62 \mathrm{~b}$ \\
3 (Topo) & $11,72 \mathrm{~b}$ \\
\hline Situações & Penetrações (mm) \\
\hline (1) Não-invertida & $13,58 \mathrm{~b}$ \\
(2) Invertida & $20,03 \mathrm{a}$ \\
\hline
\end{tabular}

As médias seguidas pela mesma letra não diferem estatisticamente pelo teste de Tukey $(\mathrm{p} \geq 0,05)$.

Com relação à situação (invertida e não-invertida), as peças invertidas apresentaram maior penetração que aquelas não-invertidas. Isso ocorreu porque a inversão homogeneizou a penetração do cobre ao longo da peça, além de ter proporcionado uma maior penetração no topo das peças.

\subsection{Retenção do CCB nas peças tratadas}

A retenção média obtida na base das peças nãoinvertidas (Tabela 4) foi 1,85 vezes maior que a obtida nas peças invertidas. No meio das peças, os valores obtidos para as peças invertidas e não-invertidas foram semelhantes. No entanto, no topo das peças, as invertidas atingiram um valor 2,64 vezes maior que nas não-invertidas.
Como a base e o topo das peças são as áreas mais propícias ao ataque de organismos xilófagos, principalmente em peças instaladas ou em contato com o solo ou locais úmidos, a inversão das peças nas soluções preservativas pode proporcionar melhor proteção à madeira, fato já relatado por outros autores, dentre eles Farias Sobrinho et al. (2005), Magalhães e Pereira (2003) e Paes et al. (2005).

A análise estatística dos dados (Tabela 5) indicou que a posição nas peças e a interação entre posição e situação (invertida e não-invertida) foram significativas. A interação foi desdobrada e analisada pelo teste de Tukey a 5\% (Tabela 6).

Observa-se, ao se analisar o efeito das situações em cada posição na peça (Tabela 6), que, para as peças não-invertidas, a retenção na posição $1(50 \mathrm{~cm}$ da base das peças) foi superior às obtidas para as posições 2 e 3; por outro lado, para as invertidas, não houve diferença significativa para as posições analisadas, embora as amostras obtidas da base e topo tenham alcançado uma retenção numericamente superior à do meio da peça.

Com a inversão, obteve-se uma retenção mais homogênea do produto preservativo ao longo da peça, além de um reforço suplementar no topo das mesmas; isto é vantajoso, pois peças instaladas no campo têm o topo deteriorado pela ação de xilófagos, por causa das reações provocadas pelos raios solares e lixiviação causada pela chuva, quando uma baixa retenção é alcançada nesta posição da peças.

Tabela 4 - Retenção de CCB ( $\mathrm{kg}$ i.a. $\left./ \mathrm{m}^{3}\right)$ para as situações e posições nas peças tratadas.

Table 4 - Retention of CCB $\left(\mathrm{kg}\right.$ a.i. $\left./ \mathrm{m}^{3}\right)$ for the situations and positions in treated pieces.

\begin{tabular}{lccccc}
\hline \multirow{2}{*}{ Situações } & \multicolumn{2}{c}{ Retenções Medidas por Posição $\left(\mathrm{kg} / \mathrm{m}^{3}\right)$} & \multicolumn{2}{c}{ Retenção na Peça $\left(\mathrm{kg} / \mathrm{m}^{3}\right)$} \\
\cline { 2 - 5 } & 1 (Base) & 2 (Meio) & $3($ Topo $)$ & Média & $\mathrm{CV}(\%)$ \\
\hline \multirow{2}{*}{ Não-invertida } & 19,96 & 8,75 & 3,21 & 10,64 & 80,17 \\
& 14,27 & 5,41 & 5,21 & 8,30 & 62,29 \\
\hline Média & 26,65 & 10,10 & 5,26 & 14,00 & 80,14 \\
CV (\%) & 20,29 & 8,09 & 4,56 & 10,98 & 74,20 \\
\hline \multirow{2}{*}{$(2)$} & 30,56 & 29,79 & 25,66 & 29,69 & 13,91 \\
Invertida & 7,60 & 4,11 & 9,38 & 7,03 & 38,26 \\
& 16,02 & 15,79 & 13,55 & 15,12 & 72,99 \\
\hline Média & 9,23 & 1,69 & 13,15 & 8,02 & 39,94 \\
CV (\%) & 10,95 & 7,20 & 12,03 & 10,06 & 79,67 \\
\hline
\end{tabular}

Cerne, Lavras, v. 17, n. 2, p. 275-282, abr./jun. 2011 
Tabela 5 - Análise de variância da retenção do CCB (kg i.a./ $\mathrm{m}^{3}$ ) nas peças tratadas.

Table 5 - Variance analysis to CCB retention $\left(\mathrm{kg}\right.$ a.i. $\left./ \mathrm{m}^{3}\right)$ in treated pieces.

\begin{tabular}{lcccc}
\hline $\begin{array}{l}\text { Fonte de } \\
\text { Variação }\end{array}$ & $\begin{array}{c}\text { Graus de } \\
\text { Liberdade }\end{array}$ & $\begin{array}{c}\text { Soma de } \\
\text { Quadrados }\end{array}$ & $\begin{array}{c}\text { Quadrados } \\
\text { Médios }\end{array}$ & F \\
\hline Situação & 1 & 3,84 & 3,84 & $0,18^{\text {Ns }}$ \\
Posição & 2 & 235,46 & 117,73 & $5,54^{*}$ \\
Sit x Pos & 2 & 211,85 & 105,93 & $4,98^{*}$ \\
Resíduo & 12 & 255,05 & 21,25 & \\
Total & 17 & 706,20 & & \\
\hline
\end{tabular}

* Significativo a $5 \%$ de probabilidade; ${ }^{\text {NS }}$ não significativo a $5 \%$ de probabilidade.

Tabela 6 - Comparações entre as retenções de CCB (kgi.a. $\left./ \mathrm{m}^{3}\right)$ nas peças tratadas.

Table 6 - Comparisons among CCB retentions $\left(\mathrm{kg}\right.$ a.i. $\left./ \mathrm{m}^{3}\right)$ on treated pieces.

\begin{tabular}{lccr}
\hline \multirow{2}{*}{ Situações } & \multicolumn{3}{c}{ Posições nas Peças } \\
\cline { 2 - 4 } & 1 (Base) & 2 (Meio) & 3 (Topo) \\
\hline (1) Não-invertida & $20,29 \mathrm{Aa}$ & $8,09 \mathrm{Ba}$ & $4,56 \mathrm{Bb}$ \\
(2) Invertida & $10,95 \mathrm{Ab}$ & $7,20 \mathrm{Aa}$ & $12,03 \mathrm{Aa}$ \\
\hline
\end{tabular}

As médias seguidas da mesma letra, maiúscula na horizontal, ou minúscula na vertical, não diferem estatisticamente pelo testes de Tukey $(p \geq 0,05)$.

Ao se considerar a posição das peças em cada situação (Tabela 6), foi observado, para a posição 1 (base), que a retenção foi superior nas peças não-invertidas, haja vista que a base passou todo o período de tratamento em contato com a solução preservativa, ao contrário das peças invertidas, em que cada extremidade passou uma parte do tempo mergulhada na solução e outra em contato com o ar. Para a posição 2, as situações (invertida ou nãoinvertida) não causaram efeito significativo; no entanto, para a posição 3, as peças invertidas apresentaram maior retenção que as não-invertidas.

As retenções obtidas, exceto a da posição 3 (próximo ao topo) das peças não-invertidas, foram superiores à mínima recomendada pela ABNT (2009), a qual estabelece uma retenção mínima de $6,5 \mathrm{~kg}$ de ingredientes ativos $/ \mathrm{m}^{3}$ de madeira tratada, para que as peças possam ser utilizadas em contato direto com o solo ou em situações de alto risco de deterioração.

\section{CONCLUSÕES}

A penetração média atingida pelas peças (nãoinvertidas ou invertidas) durante o tratamento foi superior à mínima recomendada. As peças não-invertidas tiveram uma maior retenção próxima à base. No topo foi observada uma penetração inferior à recomendada pela Associação Brasileira de Normas Técnicas para madeiras a serem empregadas em contato com o solo. Nas peças invertidas, não houve diferença entre a retenção nas diferentes posições nas peças tratadas.

A distribuição, penetração e retenção do preservativo $\mathrm{CCB}$, ocorreram de forma mais homogênea nas peças que foram invertidas, uma vez que a parte superior (topo) recebeu mais solução preservativa em comparação com as peças não-invertidas.

\section{REFERÊNCIAS}

ASSOCIAÇÃO BRASILEIRA DE NORMAS TÉCNICAS. NBR 6232: penetração e retenção de preservativos em postes de madeira. Rio de Janeiro, 1973. 12 p.

\section{ASSOCIAÇÃO BRASILEIRA DE NORMAS TÉCNICAS. NBR 9480: peças roliças preservadas de eucalipto para construções rurais: requisitos. Rio de Janeiro, 2009. 12 p.}

AZEREDO, N. R. S. Atual situação de oferta e demanda de matéria prima de reflorestamento. In: SEMINÁRIO SOBRE PROCESSAMENTO E UTILIZAÇÃO DE MADEIRA DE REFLORESTAMENTO, 2., 1988, Curitiba. Anais... Curitiba, 1988. p. 120-138.

CALIL JÚNIOR, C.; DIAS, A. A. Utilização da madeira em construções rurais. Agriambi, Campina Grande, v. 1, n. 1, p. 71-77, 1997.

FARIAS SOBRINHO, D. W.; PAES, J. B.; FURTADO, D. A. Tratamento preservativo da madeira de algaroba (Prosopis juliflora (Sw) D.C.), pelo método de substituição de seiva. Cerne, Lavras, v. 11, n. 3, p. 225-236, 2005.

FERREIRA, M. A contribuição do setor de sementes do LCF/ IPEF para a silvicultura intensiva brasileira. IPEF, Piracicaba, n. 46, p. $8-31,1993$.

FLYNN, B.; SHIELD, E. Eucalyptus progress in higher value utilization: a global review. Tacoma: R. Flynn, 1999. 212 p.

Cerne, Lavras, v. 17, n. 2, p. 275-282, abr./jun. 2011 
HUNT, G. M.; GARRATT, G. A. Wood preservation. 3. ed. New York: McGraw-Hill, 1967. 433 p.

MAGAlHÃES, W. L. E.; PEREIRA, J. C. D. Método de substituição de seiva para preservação de mourões. Colombo: EMBRAPA, 2003. (Comunicado técnico, 97).

MORESCHI, J. C. Ensaios biológicos: uma nova alternativa para a determinação dos ingredientes ativos do preservativo CCA e estudos de interações. 1985. 128 f. Tese (Doutorado) Universidade Federal do Paraná, Curitiba, 1985.

PAES, J. B.; MORESCHI, J. C.; LELLES, J. G. Avaliação do tratamento preservativo de moirões de Eucalyptus viminalis Lab. e de bracatinga (Mimosa scabrella Benth.) pelo método de substituição da seiva. Ciência Florestal, Santa Maria, v. 15, n. 1, p. 75-86, 2005.
SILVA, P. H. M. Tratamento e secagem da madeira. Piracicaba: IPEF, 2005. Disponível em: <http://www.ipef.br/tecprodutos/ tratamento_secagem_madeira.asp>. Acesso em: 1 fev. 2008.

TEREZO, E. F. M. Reflorestamentos em regiões tropicais. In: CONGRESSO INTERNACIONAL DE COMPENSADO E MADEIRA TROPICAL, 5., 2001, Belém. Anais... Belém: ABIMCI/AIMEX/FIEPA, 2001. CD-ROM.

VITAL, B. R. Métodos de determinação da densidade da madeira. Viçosa, MG: UFV, 1984. 21 p. (Boletim técnico, 1).

WEHR, J. P. P. Métodos práticos de tratamento preservativo de moirões roliços de Pinus caribaea Morelet var. hondurensis Bar et Golf. 1985. 209 f. Dissertação (Mestrado em Engenharia Florestal) - Escola Superior de Agricultura “Luiz de Queiroz”, Piracicaba, 1985. 